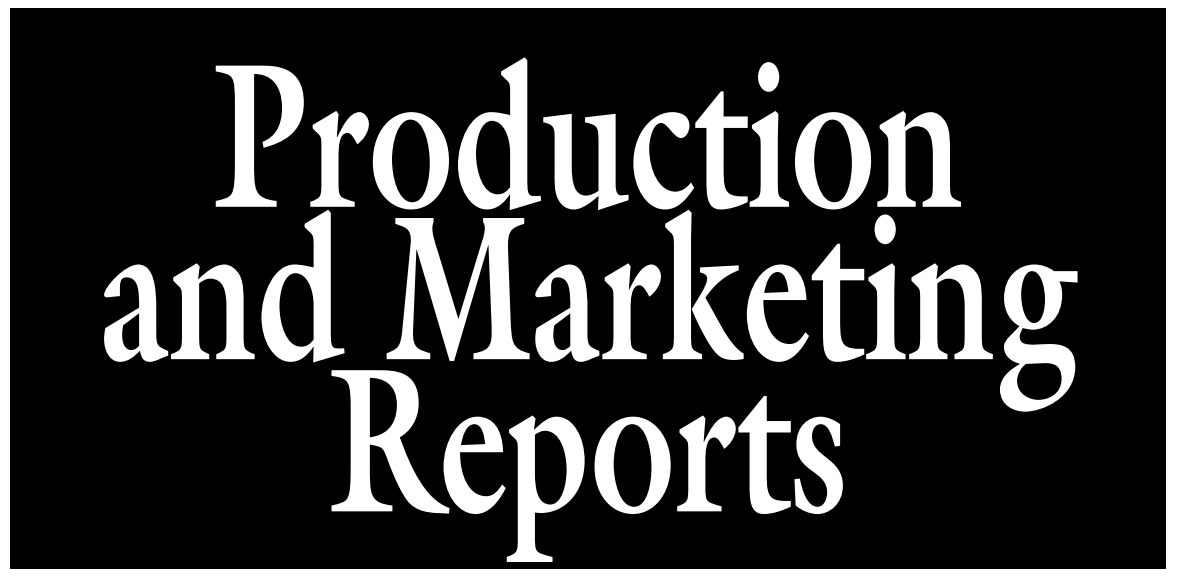

\title{
Economic Potential of Producing Tahiti Limes in Southern Florida in the Presence of Citrus Canker and Citrus Greening
}

\author{
Edward A. Evans ${ }^{1,2}$, Fredy H. Ballen ${ }^{1}$, and Jonathan H. Crane ${ }^{1}$
}

AdDitional index words. Citrus latifolia, Florida lime industry, persian lime, stochastic budgeting, stop light analysis

Summary. This article assesses the profitability of a hypothetical 5-acre tahiti lime (Citrus latifolia) orchard in southern Florida in the presence of citrus canker (Xanthomonas axonopodis pv. citri) and citrus greening [Candidatus Liberibacter asiaticus (LAS)]. To account for the uncertainty associated with the presence of these diseases, a stochastic budgeting technique was employed in the analysis, incorporating stochastic prices and yields based on discussions with industry experts and researchers. The analysis focused on three possible types of management strategies currently practiced by citrus (Citrus sp.) growers in Florida: 1) production without any specific control activities for citrus canker and citrus greening, 2) canker and greening management without removal or replacement of infected/ suspicious trees, and 3) canker and greening management with removal and replacement of infected trees. The analysis was carried out for a 20 -year time horizon and average net return per acre and rate of return on investment were considered. The results suggest that despite the presence of disease, it would be profitable to produce tahiti limes in southern Florida. This is because the tahiti lime offers some resistance to both citrus greening and canker and will produce even if minimal attention is paid to controlling the diseases. Of the three management strategies investigated, strategy 2 offers the best prospect in terms of high net returns and highest probability of achieving or surpassing the desired rates of return on investment of $12 \%$ per annum. The key finding from the study is that the production of tahiti limes in southern Florida can be profitable if steps are taken to manage the diseases, but contrary to popular view, it might be better to wait until the trees become fully unproductive before disposing of them.

$\mathrm{T}$ wo types of limes are mainly consumed in the United States, namely tahiti limes (also called persian limes) and key limes (Citrus aurantifolia). Tahiti limes are generally larger and contain more juice than do key limes, but have a shorter shelf life. Over the years, U.S. consumers

${ }^{1}$ University of Florida, Tropical Research and Education Center, 18905 SW 280th Street, Homestead, FL 33031

${ }^{2}$ Corresponding author. E-mail: eaevans@ufl.edu. have shown a definite preference for tahiti limes by a ratio of $\approx 9: 1$ [U.S. Department of Agriculture (USDA),
2013]. Between 1980 and 2011, consumption of fresh limes in the United States increased from 43.6 to 365.4 thousand tonnes $(99 \%$ are imports). This corresponds to a rise in per capita consumption from less than 0.5 to nearly $2.6 \mathrm{lb}$ over the same period, representing an annual growth rate of $\approx 6 \%$ (USDA, 2013). The noticeable increase in the level of consumption of fresh limes observed in the United States can be attributed in part to a growing Hispanic population and the opening up of the market to imports from Mexico. Currently, the United States is the largest single-country importer of fresh limes, absorbing close to $18 \%$ of the global trade of limes and lemons (Citrus limon) in 2011 (Food and Agriculture Organization of the United Nations, 2012). The vast majority (more than $90 \%$ ) of imported limes is supplied by Mexico — the world's leading producer and exporter of limes-with the remainder being sourced from suppliers in Central and South American countries.

The overwhelming dependence on imports to satisfy U.S. domestic demand for fresh limes was not always the case. As recently as 1990, the United States satisfied more than half of it domestic needs from local production (Spreen, 2000), with the bulk of production (more than $90 \%$ ) occurring in southern Florida (Miami-Dade County) and smaller quantities being produced in the southern parts of California and Texas-production is limited to these areas because of the crop being extremely cold-sensitive. The noticeable shift in the degree of reliance on U.S. domestic production is attributed to several factors. Chief among these factors are increased foreign competition, adverse weather conditions (such as drought), natural disasters (such as hurricanes), and outbreaks of pests and diseases (Roy et al., 1996; Spreen, 2000; C. Wheeling, personal communication). A devastating natural disaster was Hurricane Andrew,

\begin{tabular}{llll}
\hline $\begin{array}{l}\text { Units } \\
\text { To convert U.S. to SI, } \\
\text { multiply by }\end{array}$ & U.S. unit & SI unit & $\begin{array}{l}\text { To convert SI to U.S., } \\
\text { multiply by }\end{array}$ \\
\hline 0.4047 & $\mathrm{acre}(\mathrm{s})$ & $\mathrm{ha}$ & 2.4711 \\
0.3048 & $\mathrm{ft}$ & $\mathrm{m}$ & 3.2808 \\
0.4536 & $\mathrm{lb}$ & $\mathrm{kg}$ & 2.2046 \\
1.1209 & $\mathrm{lb} / \mathrm{acre}$ & $\mathrm{kg} \cdot \mathrm{ha}^{-1}$ & 0.8922 \\
0.9072 & ton $(\mathrm{s})$ & tonne $\left.^{-1}\right)$ & 1.1023
\end{tabular}


a category 5 hurricane, which struck the main lime-producing areas of Florida in 1992, destroying most of its industry. The extent of the hurricane's damage is reflected in the data showing that the number of bearing trees declined from almost 1 million trees before the hurricane to a little more than 0.25 million trees after the hurricane, with production falling from $\approx 58,000$ tons to $\approx 8000$ tons. Correspondingly, the farm gate value fell from $\approx \$ 20$ million to $\approx \$ 2.5$ million (Spreen, 2000). Foreign competition has become a huge problem since 1994, when the United States signed the North American Free Trade Agreement, which opened the market to imports from its competitor, Mexico. This served to further aggravate the situation at a time when many Florida growers had embarked on an ambitious replanting program following the 1992 hurricane (M. Philcox, personal communication; C. Wheeling, personal communication).

However, despite these setbacks, the industry was poised for a recovery (J.H. Crane, personal communication; T.H. Spreen, personal communication; C. Wheeling, personal communication) when it suffered the most severe blow yet with the discovery of the citrus canker disease in the main limeproducing area. At that time, the relative resistance (tolerance) of tahiti lime to citrus canker was not known and therefore (Crane and Osborne, 2011; Dewdney et al., 2009; Folimonova et al., 2009; Spann et al., 2008a, 2008 b), intense fear that the diseases would spread and jeopardize the $\$ 9$ billion Florida citrus industry led to the implementation of an aggressive eradication program that lasted from 2002 to 2006. This eradication program involved the destruction of all citrus trees grown in Miami-Dade County and the enforcement of regulations prohibiting the growing of any citrus trees (commercial or otherwise) in the area [Florida Department of Agriculture and Consumer Services (FDACS), 2013]. A consequence of the program was that hundreds of thousands of citrus trees had to be destroyed, causing tremendous financial losses to growers, notwithstanding the partial compensation offered by federal and state efforts to mitigate the impact. As a result, Mexico took full advantage of the market opportunity (Fig. 1).

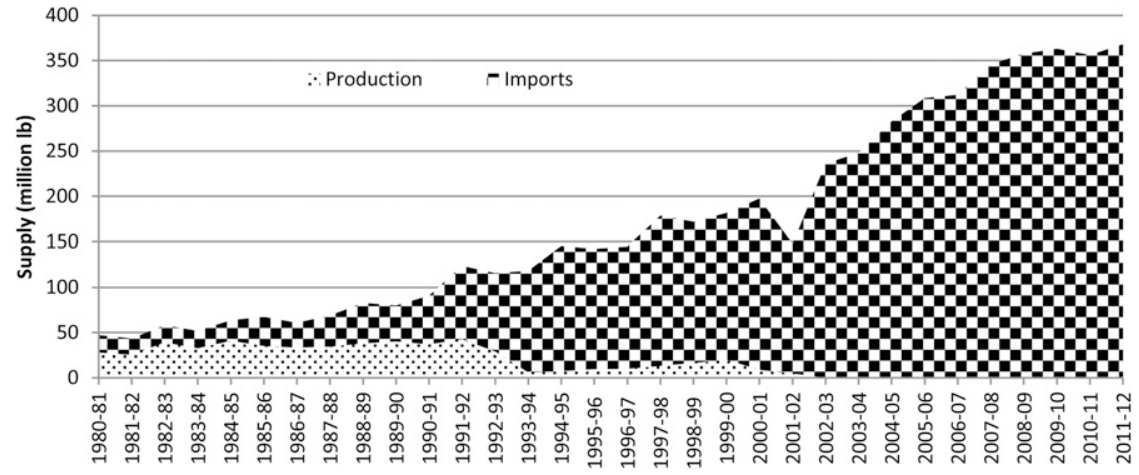

Fig. 1. U.S. fresh tahiti lime supply from 1980-81 to 2011-12. The figure shows that the bulk of the fresh tahiti limes consumed in the United States is imported (U.S. production ended in 2002 because of mandatory eradication program); $1 \mathrm{lb}=$ $0.4536 \mathrm{~kg}$.

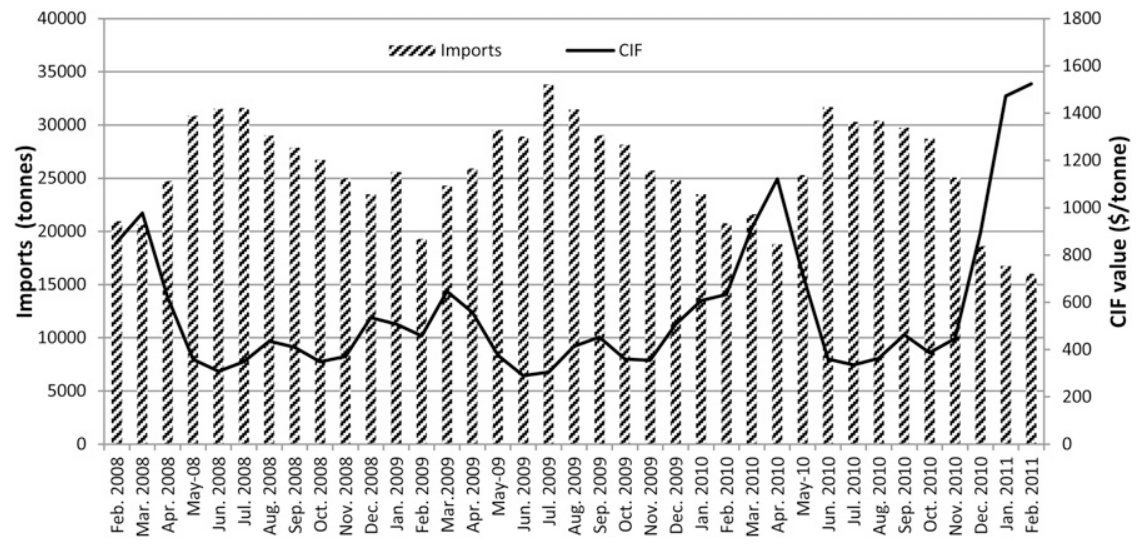

Fig. 2. Quantities of tahiti limes imported from Mexico and monthly cost, insurance, and freight price (CIF) values for the period Feb. 2008 to Feb. 2011. The $y$-axis to the left represents the quantities as shown in the bar graph, and the $y$-axis to the right represents the values as shown in the line graph; 1 tonne $=1.1023$ ton, $\$ 1$ / tonne $=\$ 0.9072 /$ ton .

Times have changed though. The mandatory eradication program ended in 2006, and most of the restrictions on cultivation of the crop have been removed (except for a few dealing with the sourcing of nursery stocks, which can only be purchased from certified nurseries) (FDACS, 2013). However, recent supplies of tahiti limes from Mexico have been experiencing frequent shipping interruptions because of phytosanitary issues and adverse growing conditions in Mexico, causing shortages of tahiti limes on the U.S. domestic market and extreme price volatility (Fig. 2). For example, the cost, insurance, and freight price (CIF) for tahiti limes imported from Mexico has increased significantly, from $\$ 854 /$ tonne in Feb. 2008 to $\$ 1524 /$ tonne in Feb. 2011 , because of phytosanitary issues in Mexico, such as sweet orange scab
(Elsinoë australis) and citrus greening (FreshFruitPortal.com, 2011). Further stoking the interest of prospective U.S. producers are results of a demonstration plot of tahiti limes at the University of Florida Tropical Research and Education Center in Homestead, which have shown that reasonable yields of tahiti limes can be obtained despite the presence of citrus canker and citrus greening even in the absence of any specific control activities for the diseases (J. Pena, personal communication).

Given the renewed interest in tahiti lime production in southern Florida, the objective of this article is to assess the profitability of a hypothetical 5-acre tahiti lime orchard in southern Florida in the presence of citrus canker and citrus greening. To account for the uncertainty associated with the presence of the diseases, 
a stochastic budgeting technique is employed in the analysis, incorporating stochastic prices and yields based on discussions with industry experts and researchers. The analysis is focused on three possible types of management strategies currently practiced by citrus growers in Florida: 1) production without any specific control activities for citrus canker and citrus greening, 2) canker and greening management without immediate removal or replacement of infected/suspicious trees, and 3) canker and greening management with immediate removal and replacement of infected trees (Morris and Muraro, 2008). The analysis is carried out for a 20-year time horizon.

\section{Biological impacts and management of citrus canker and citrus greening diseases}

Citrus canker is a serious disease of all citrus cultivars and some citrus relatives, but is not harmful to humans or animals. The bacterium causes necrotic lesions on leaves, stems, and fruit of infected trees. Canker lesions on fruit may cause premature fruit drop, thus reducing fruit yield, and giving the fruit an unappealing appearance (Spann et al., 2008a). However, canker lesions on fruit are only "skin deep" and the fruit is still edible. Severe cases can cause defoliation, twig dieback, and general tree decline. Management of citrus canker involves using one or more of the following: defoliation and pruning, tree removal, windbreaks, and copper sprays (Dewdney and Graham, 2012). With respect to copper sprays, Dewdney et al. (2009) point out that chemical treatment is expensive because the copper products act only as a chemical barrier against canker infection and are not systemic, whereby the treatment has to be applied routinely to the surface of the trees as they grow and mature (Dewdney and Graham, 2012). While citrus canker affects all types of citrus, there is evidence to suggest that tahiti limes are less susceptible (Spann et al., 2008a).

Citrus greening, also known as Huanglongbin (HLB), is a bacterial disease with far worse consequences than citrus canker. Whereas canker makes the trees less productive and blemishes the fruit, HLB causes the fruit to be totally unusable and eventually kills the trees. This disease has severely limited the production in many citrus-growing areas around the world. The dreaded disease was discovered in Florida in Aug. 2005, and has since become endemic (Spann et al., 2008b, 2010). In Florida, LAS is spread by the asian citrus psyllid (Diaphorina citri). LAS is a phloemlimited bacterium that appears to cause phloem plugging and likely has other undetermined effects on infected trees. Phloem plugging disrupts carbohydrate transport within the tree, which causes tree decline. Symptomatic trees display visual symptoms of "blotchy mottle leaf chlorosis," and may produce small, lopsided fruit that fail to ripen and drop prematurely. Juice from fruit displaying these symptoms is similar in quality to juice from less mature fruit (Spann et al., 2008b, 2010).

A major problem with HLB is that infected and contagious trees do not show symptoms for several years. Management of HLB involves a combination of inoculum reduction via removal of HLB-infected trees, control of the asian citrus psyllids, and/or the use of foliar nutritional sprays to maintain the productivity of HLB-infected trees. Morris and Muraro (2008) observed that when HLB is detected early enough and control practices are followed diligently, sweet orange ( Citrus sinensis) groves can remain productive with disease incidence at a low level. They concluded that the key is early detection, followed by effective control practices. They further noted that a management strategy that combines the removal of severely infected trees with the replacement of new trees and aggressive efforts to protect the resets can give perpetual life to the grove, and does not require the investment of capital and lost income of replanting the entire grove (Morris and Muraro, 2008). Studies have shown that tahiti lime trees offer some resistance to both diseases and that reasonable yield can be obtained even in the presence of the diseases and with minimal to no control activities (J.H. Crane, unpublished data; Folimonova et al., 2009).

\section{Methodology, main assumptions, and scenarios}

Information used in the analysis was obtained from a combination of interviews (35) with growers, nursery operators, packinghouses, chemical suppliers, and other agricultural input vendors in the Homestead area of Florida, expert opinions from University of Florida researchers and extension agents, and the existing literature. Several assumptions were used in the model regarding production, harvesting, and marketing costs.

In the study, it was assumed that a grower already owned the land or that the land could be rented for $\$ 500 /$ acre (the existing rental rate in Miami-Dade County). The budget and production costs were based on a 5-acre orchard (the minimum size farm allowed for commercial citrus growers in Florida). A planting density for the tahiti lime trees was 168 trees/acre, with a distance of $13 \mathrm{ft}$ between trees in rows $20 \mathrm{ft}$ apart. The trees received four fertilizer treatments per annum of an $8 \mathrm{~N}-3.5 \mathrm{P}-$ $6.6 \mathrm{~K}$ fertilizer at a rate of 64 to 192 $\mathrm{lb} /$ acre. Under scenarios 2 and 3, a commercial nutritional spray was assumed to be applied six times per annum. Weed management consisted of four applications per annum of glyphosate (Roundup PowerMax ${ }^{\circledR}$; Monsanto, St. Louis, MO) applied at a rate of $11 \mathrm{lb} /$ acre within the rows. In addition, rows were mowed six times per annum at a total cost of $\$ 120 /$ acre. Pest management consisted of a combination of chemicals at \$242/ acre. Each orchard had a well and piped irrigation system. The cost of digging the well and installing the piped irrigation system was estimated at $\$ 12,650 /$ orchard. The annual recurrent irrigation costs, which include the costs of pumping water and maintenance labor, were estimated at $\$ 50 /$ acre. Production labor consisted of skilled $(\$ 15 / \mathrm{h})$ and unskilled/field workers $(\$ 12 / \mathrm{h})$ as reported by the growers. Labor rates included fringe benefits such as Worker's Compensation, Social Security, Medicare, and health insurance. Piece-rate wage rates were used for harvesting. Harvesting and marketing costs included the cost for harvesting and transporting tahiti limes to the packing house at a rate of $\$ 3.50$ per $55-\mathrm{lb}$ bushel, as reported by the growers. It should be noted that the labor rates used were higher (and thus more conservative) than either the agricultural labor rates reported by the Federal Bureau of Labor Statistics or the Adverse Wage 
Rates reported by the state Department of Labor for Florida. As of 1 Jan. 2013, the Florida minimum wage rate is $\$ 7.79 / \mathrm{h}$, compared with the federal minimum wage rate of $\$ 7.25 / \mathrm{h}$. Yield was based on historic data before the discovery of citrus canker and citrus greening diseases and was assumed to follow a uniform distribution. Price represented the 3-year (2009-11) average landed price of tahiti limes (Homestead) from Mexico and was assumed to follow the Gray, Richarson, Klose, and Schuman distribution (GRKS). The GRKS distribution was developed to simulate subjective probability distributions based on minimal input data (Richardson, 2006).

The financial analysis was based on a discounted cash flow layout, with annual time steps and a maximum evaluation period of 20 years. The cash flow analysis was built around the following three areas: 1) investment inputs, 2) variable (recurrent) inputs, and 3 ) returns and residual values. The model used the wellknown key output variable of internal rate of return (IRR) (Barry et al., 2000 ). A $12 \%$ rate of return was considered to be the lower cut-off point for the grove to be considered profitable given the inherent risks associated with the enterprise. A return above $15 \%$ was considered by several growers to be desirable. These rates were chosen based on the response of growers as to what was considered a desirable rate of return to restart cultivating the crop. The rates also reflect those commonly found in the literature assessing the economic life of commercial citrus groves (Morris et al., 2011).

The stochastic budget used follows the approach outlined by Richardson (2006) and involves several steps. First, probability distributions were assigned to the variables affected by the risk factors, namely prices and yield. Second, the stochastic values sampled from the probability distributions were used in the accounting equations to calculate production, receipts, net returns, and IRR. Third, the completed stochastic budget was simulated 500 times using the random values for the risky variables. The results of the 500 samples provided the information to estimate the empirical probability distribution for the unobserved IRR. This information can be further analyzed using a cumulative distribution function (CDF) of the IRR and a "stop light" graph. The stop light graph uses the CDF information but expresses it in the form of the "probability of achieving a target value," which is easier to understand. The model was programmed in Excel (Microsoft Corp., Redmond, WA) and simulated using the Excel Add-In, Simulation \& Econometrics to Analyze Risk $^{\odot}$ (Simetar, College Station, TX).

As mentioned earlier, both the uniform distribution and the GRKS distribution were chosen to model the yield and price variables, respectively. Among other things, these distributions were chosen given the limited amount of information needed to generate the random variable. The uniform distribution is one for which the probability of occurrence is the same for all possible outcomes. The population of a continuous uniform distribution is defined by a minimum and a maximum value. The GRKS distribution is a two-piece normal distribution, with $50 \%$ of the weight below the middle (median) value and $2 \%$ less than the minimum, and $50 \%$ above the middle value and $2 \%$ above the maximum. The population can therefore be defined given the minimum, middle (median), and maximum values. The distribution is used in place of a triangular distribution when one knows only minimum information about the random variable (Richardson, 2006).

Based on discussions with growers and extension specialists, yield variable was modeled in relation to maximum yields that were obtained in the production area in the absence of the diseases. Specifically, for each scenario (discussed below), the maximum yields obtained in the absence of the diseases as well as the minimum and maximum percentage per year for a given management scenario (Table 1). For example, whereas, in the absence of the disease, maximum yield obtainable in year three was $15,236 \mathrm{lb} / \mathrm{acre}$, under scenario 1 , the maximum was estimated at $13,712 \mathrm{lb} /$ acre and the minimum was $12,951 \mathrm{lb} /$ acre, representing $90 \%$ and $85 \%$, respectively, of

Table 1. Using the biological parameters in the model for each of the three tahiti lime management scenarios the expected minimum and maximum percentage of base yield (yield without disease) that is likely in the presence of citrus canker and Huanglongbin. For example, under management strategy 1 , during year 3, it is expected that the yield obtained will be $85 \%$ to $90 \%$ of the yield that was obtained $(15,236 \mathrm{lb} / \mathrm{acre})$ in absence of the diseases.

\begin{tabular}{|c|c|c|c|c|c|c|c|}
\hline \multirow[b]{3}{*}{$\underline{\mathbf{Y r}}$} & \multirow{3}{*}{$\begin{array}{l}\text { Yield without } \\
\text { disease } \\
(\text { lb } / \text { acre })^{z}\end{array}$} & \multicolumn{2}{|c|}{$\begin{array}{l}\text { Scenario } 1 \\
(\text { no control })^{\mathrm{y}}\end{array}$} & \multicolumn{2}{|c|}{$\begin{array}{c}\text { Scenario } 2 \\
(\text { control only })^{x}\end{array}$} & \multicolumn{2}{|c|}{$\begin{array}{c}\text { Scenario 3 } \\
\left(_{(\text {control }+ \text { tree replacement })^{\mathrm{w}}}\right.\end{array}$} \\
\hline & & Minimum & Maximum & Minimum & Maximum & Minimum & Maximum \\
\hline & & \multicolumn{6}{|c|}{ (\% base yield) } \\
\hline 1 & 1,956 & 85 & 90 & 95 & 99 & 97 & 100 \\
\hline 2 & 8,415 & 85 & 90 & 95 & 99 & 97 & 100 \\
\hline 3 & 15,236 & 85 & 90 & 95 & 99 & 97 & 100 \\
\hline 6 & 29,921 & 70 & 80 & 88 & 90 & 93 & 96 \\
\hline 7 & 37,127 & 70 & 80 & 88 & 90 & 93 & 93 \\
\hline $8^{+}$ & 37,567 & 35 & 70 & 68 & 87 & 90 & 93 \\
\hline
\end{tabular}

${ }^{2}$ Yields obtained in the absence of the diseases; $1 \mathrm{lb} /$ acre $=1.1209 \mathrm{~kg} \cdot \mathrm{ha}^{-1}$.

yroduction without any specific control activities for citrus canker and citrus greening, which is equivalent to the "do nothing" management strategy. Tree loss is estimated at the average rate of $5 \%$ per annum, with no replacement, no nutritional spray, nor attempts to control asian citrus psyllids.

${ }^{x}$ Canker and greening management but no removal or replacement of infected/suspicious trees, and trees are allowed to bear out until they are dead. Tree losses are assumed to occur at an average rate of $2 \%$ per annum, with no replacement, but with applications of nutritional spray and a special spray program to control asian citrus psyllids

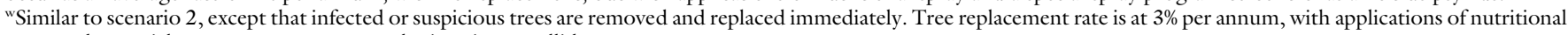
spray and a special spray program to control asian citrus psyllids. 
the maximum $(15,236 \mathrm{lb} /$ acre $)$ that would have been realized in the absence of the diseases.

The price variable was assumed to follow a GRKS distribution. In the absence of recent data on growers' prices, the estimated landed Homestead price of tahiti limes imported from Mexico was used. Specifically, we added the inland transportation costs (truck rates) (USDA, 2012a) to the annual CIF prices of limes imported at the United States-Mexican border during the period 2009-11 (USDA, $2012 \mathrm{~b}$ ). The minimum, middle (median), and maximum prices of $\$ 0.27$ / $\mathrm{lb}, \$ 0.29 / \mathrm{lb}$, and $\$ 0.33 / \mathrm{lb}$, respectively, were used to parameterize the GRKS distribution and generate the stochastic price variable. The stochastic yield multiplied by the stochastic price resulted in the stochastic gross receipts.

The costs of all recurrent inputs, with the exception of labor, were assumed to increase by $1 \%$ per annum. Many of the growers indicated that the cost of labor was increasing at a faster pace as compared with the cost of other inputs. Among other things, this was due to the increase in the minimum wage and to policies to crack down on undocumented workers. As such, the cost of labor was allowed to grow at an average annual rate of $2 \%$ over the period.

The analysis is carried out for three management strategies/practices: 1) production without any disease management program or replacement of loss trees; 2) production with a disease management program but no tree replacement; and 3 ) production with a disease management program and the immediate removal and replacement of all suspect and infected trees. Using the findings of Muraro (2010) with Florida citrus, an annual tree loss of $\approx \mathbf{5} \%$ is assumed under the first scenario, and $2 \%$ under the second scenario. In the case of scenario 3 , it is assumed that trees are replaced at an annual rate of $3 \%$. The canker and citrus greening management program under scenarios 2 and 3 assumes that reasonable steps are taken to manage the diseases using a combination of early detection involving scouting, chemical sprays to protect against asian citrus psyllids, and the use of a nutritional spray program somewhat similar to that employed for other citrus cultivars. The main difference between scenarios 2 and 3 is that in the case of the latter, once a tree appears to be infected it is removed and replaced.

\section{Results and discussion}

The percentage of the expected maximum yield per year varies by management scenario: scenario $1-$ no control (do nothing); scenario 2-control for citrus canker and greening without tree replacement; and scenario 3 - control for citrus canker and greening with tree replacement (Table 1). The financial summary statistics for each of the three scenarios revealed that scenario 3 had the highest mean net returns of $\$ 2466 /$ acre, which exceeded the returns from scenarios 1 and 2 by $\$ 1284 /$ acre $(108.6 \%)$ and $\$ 174 /$ acre $(7.6 \%)$, respectively (Table 2). However, scenario 3 had the highest SD and CV. This indicates a larger degree of risk relative to expected return; in other words, there could be dramatic fluctuations in net returns because the grower is taking on more risk to realize the higher net income. In contrast, scenario 2 had the lowest $\mathrm{SD}$ and $\mathrm{CV}$, implying a more stable expected net income. Based on the mean $\mathrm{SD} / \mathrm{CV}$, the grower would have no incentive to employ the management strategy associated with scenario 1 since it had both the lowest mean net return per acre and a SD and $\mathrm{CV}$, which are higher than those obtained in the case of scenario 2 .

Comparing the maxi-min (i.e., the maximum of the minimum) indicates that scenario 2 would be the preferred management strategy since it had the largest minimum net return of $\$ 1870 /$ acre, compared with \$702/ acre and $\$ 1349 /$ acre for scenarios 1 and 3 , respectively. However, if the maxi-min decision criterion is employed, then scenario 3 emerges as the preferred one, with net revenue of $\$ 3169 /$ acre, compared with scenarios 1 and 2, which had maximum net returns of $\$ 1653 /$ acre and $\$ 2661 /$ acre, respectively.

Although it is clear from the above analysis that a grower would be better off choosing either management strategy 2 or 3 , there is not a clear-cut basis for choosing one over the other. Moreover, since several of the growers stated that they would be reluctant to resume producing tahiti limes (based on their past experience) unless they could be assured there were substantial rates of returns to be realized (i.e., that the risk was worth it), the following analysis focuses on examining this performance indicator. In particular, several of the growers indicated that they would consider returns on their investment in the vicinity of $12 \%$ to $15 \%$ to be reasonable. Figure 3 shows the rate of return CDF for the three management strategies, which includes two cut-off indicator rates at $12 \%$ and $15 \%$, respectively. These cut-off rates were chosen based on the response of growers who indicated that a desirable rate of return on investment would be $12 \%$ to $15 \%$ per annum.

The information presented in Fig. 3 shows that both management strategies 2 and 3 are preferable to management strategy 1 since both cumulative distributions lie to the right of the CDF associated with strategy 1 . In other words, for any

Table 2. A comparison of the average, $\mathrm{SD}, \mathrm{CV}$, minimum, and maximum net returns expected from 1 acre $(0.4$ ha) of tahiti lime grown in the presence of canker and Huanglongbin and under one of three management strategies.

\begin{tabular}{lccc}
\hline Measure \scenario & $\begin{array}{c}\text { Scenario 1 } \\
(\text { no control })^{\mathbf{z}}\end{array}$ & $\begin{array}{c}\text { Scenario 2 } \\
(\text { control only) }\end{array}$ & $\begin{array}{c}\mathbf{y} \\
\text { (control }+ \text { tree replacement) }^{\mathbf{x}}\end{array}$ \\
\hline Mean & $\$ 1182$ & $\$ 2292$ & $\$ 2466$ \\
$\mathrm{SD}$ & $\$ 160$ & $\$ 117$ & $\$ 360$ \\
$\mathrm{CV}^{\mathrm{w}}$ & 13.5 & 5.1 & 14.6 \\
Minimum & $\$ 702$ & $\$ 1870$ & $\$ 1349$ \\
Maximum & $\$ 1653$ & $\$ 2661$ & $\$ 3169$ \\
\hline
\end{tabular}

"Production without any specific control activities for citrus canker and citrus greening, which is equivalent to the "do nothing" management strategy. Tree loss is estimated at the average rate of $5 \%$ per annum, with no replacement, no nutritional spray, nor attempts to control asian citrus psyllids.

${ }^{y}$ Canker and greening management but no removal or replacement of infected/suspicious trees, and trees are allowed to bear out until they are dead. Tree losses are assumed to occur at an average rate of $2 \%$ per annum, with no replacement, but with applications of nutritional spray and a special spray program to control asian citrus psyllids. ${ }^{x}$ Similar to scenario 2, except that infected or suspicious trees are removed and replaced immediately. Tree replacement rate is at 3\% per annum, with applications of nutritional spray and a special spray program to control asian citrus psyllids. "The $\mathrm{CV}$, also known as "relative variability", equals the SD divided by the mean. It can be expressed either as a fraction or as a percentage and allows for comparison between data sets. It is commonly used as a measure of risk sensitivity, whereby the lower the value, the less risky the alternative. 


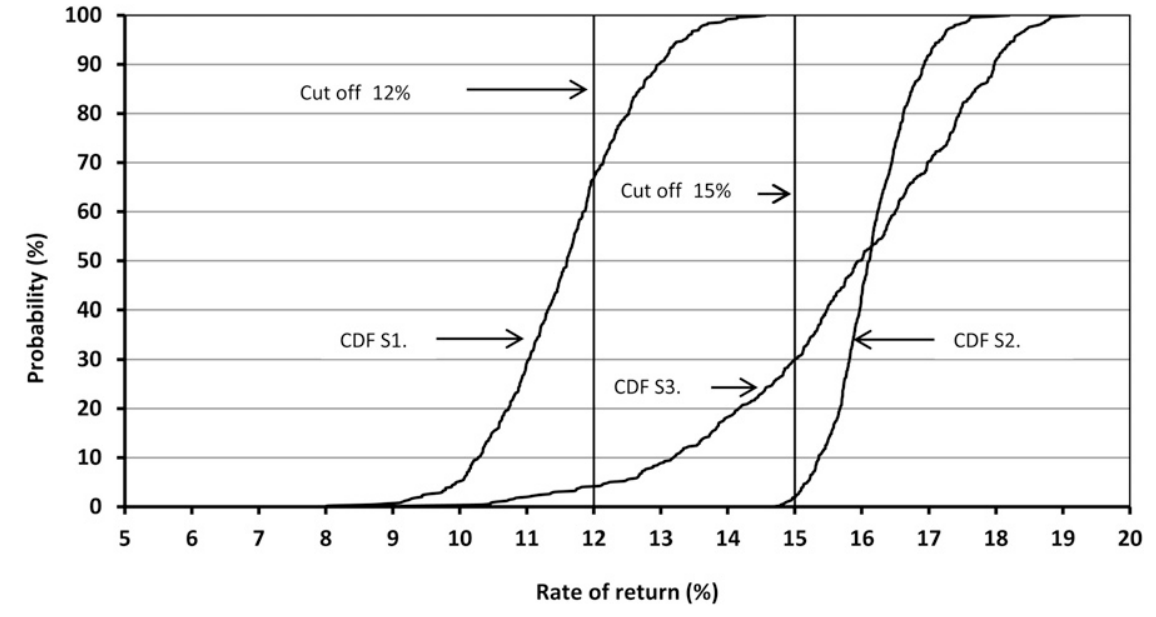

Fig. 3. Cumulative distribution functions (CDF) for each management strategy for the production of tahiti limes in southern Florida, with $12 \%$ and $15 \%$ cut-off rates of return on investment. The graph shows the likelihood (probability) of exceeding or falling below any chosen rate of return. By choosing a value on the $x$-axis and making a vertical line to the CDF for a particular management strategy $(S 1, S 2, S 3)$ and then a horizontal line to the $y$-axis, the probability that the rate of return will be less than the chosen rate can be obtained from the $y$-axis. For example, by choosing the value of $12 \%$, and making a vertical line to the CDF for S1 and then a horizontal line to the $y$-axis, it can be estimated that the chance or probability of obtaining a return on investment that is less than $12 \%$ is $\approx 67 \%$. Stated slightly different, it implies that a grower employing management strategy 1 (S1) has a $33 \%(100 \%$ to $67 \%$ ) chance of obtaining rate of return on his or her investment that will be greater than $12 \%$. Were this grower instead to consider employing management strategy 3 (S3), following the same procedure, the graph would indicate that he or she stands about a $2 \%$ chance of making less, or a $98 \%(100 \%$ to $2 \%)$ chance of obtaining more than a $12 \%$ return on his or her investment. In general, the farther to the right the $\mathrm{CDF}$, the more preferred is that risky alternative.

given rate of return, there is a higher probability or chance of obtaining a greater rate from employing either strategy 2 or 3 instead of strategy 1 . Moreover, there is a relatively high chance $(P>60 \%)$ that the rate of return obtained from strategy 1 would be less than the lower cut-off rate of $12 \%$. Both management strategies 2 and 3 have high probabilities of providing a rate of return above the lower and upper desirable rates. However, as discussed earlier, deciding between management strategies 2 and 3 is not straightforward as the two cumulative distributions crossed. Although the technique of seconddegree stochastic dominance could be used to select one of the distributions (management strategy), a more intuitive and straightforward approach involves presenting the information in the form of a stop light chart (Fig. 4) and as discussed below (Richardson et al., 2007).

The stop light analysis takes into consideration the risk preference of the grower and is suitable when the grower can identify a lower and upper cut-off point and wishes to know the likelihood of obtaining a value between these two bounds, or falling below or exceeding the lower and upper bounds, respectively. The chart displays the probabilities for a favorable and unfavorable outcome as different shadings in a stacked bar chart. The probability of achieving a favorable outcome is usually denoted as green (in this case it is shaded), while the unfavorable outcome is usually denoted as red. The probabilities of values falling between the favorable and unfavorable outcomes are usually shown in yellow (Richardson and Outlaw, 2008; Richardson et al., 2007). In the case in hand, since growers indicated a desirable rate of return of $12 \%$ to $15 \%$, these two values were used as the lower and upper bounds.

The probability or the chance of the rate of return falling within, below, or above these bounds for each of the management strategies varies (Fig. 4). In the case of management strategy 1 , there would be a $67 \%$ chance that the rate of return would be lower than $12 \%$ and a $33 \%$ chance that it would be $12 \%$ to $15 \%$. Based on the assumptions, returns are not likely to exceed

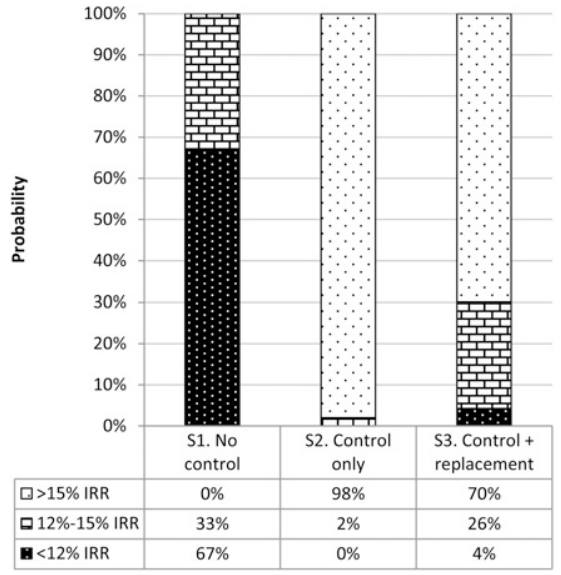

Fig. 4. Stop light analysis showing probabilities of rate of return on investment being less than $12 \%$ and greater than $15 \%$ per annum for the production of tahiti limes in southern Florida. Internal rate of return (IRR) is the average rate of return expected over the life of the project. An investment is considered profitable if the IRR is greater than an established minimum acceptable rate of return. The higher the IRR, the more profitable will be the investment. The first bar suggests that under the first scenario (S1), there is a $67 \%$ chance that the rate of return the grower obtains will be less than $12 \%$ and a $33 \%$ chance that it will be $12 \%$ to $15 \%$. The second bar suggests that under scenario 2 (S2), there is a $2 \%$ chance the returns will be $12 \%$ to $15 \%$, and a $98 \%$ chance that it will be greater than $15 \%$. The third bar suggests that under scenario 3 (S3), there is a $4 \%$ chance that the rate of return will be less than $12 \%$, a $26 \%$ percent chance that it will be $12 \%$ to $15 \%$, and a $70 \%$ chance that it will be greater than $15 \%$.

$15 \%$ if management strategy $l$ is adopted. In the case of management strategy 2 , the results suggest that there would be a $2 \%$ chance that the rate of return would be between the lower and upper limits and a 98\% chance that it would exceed the upper limit (i.e., rates of return above $15 \%$ ). Noteworthy is the implication that by adopting this approach and under the current assumptions, rates of return would not fall below the $12 \%$ mark. With respect to management strategy 3 , there is a $4 \%$ chance that the rates of return would be below the desired $12 \%$, a $26 \%$ chance that it would be $12 \%$ to $15 \%$, and a $70 \%$ chance that it would exceed the upper limit of $15 \%$.

The stop light chart therefore adds transparency to the decisionmaking process and facilitates choosing 
among the three management strategies. It shows clearly that if the decision maker is concerned with downside risks, then management strategy 2 is the best option since it is highly unlikely that the returns would ever fall below $12 \%$. Likewise, if the grower is interested in achieving higher rates of returns than the upper limit on a more consistent basis, again, it shows that management strategy 2 is the best of the three options since there is a $98 \%$ probability that the rate of returns would exceed $15 \%$. Hence, by using this technique, growers can choose the strategy that best suits their risk tolerance.

Whereas the earlier analysis was ambiguous with regards to choosing among the options, the stop light chart clearly suggests that strategy 2 is the best one. This implies that contrary to the popular belief that it is best to remove the infected tree and replace it with a new one, the results of economic and statistical analyses suggest that it might be more profitable to let the tree continue to bear fruit until it is no longer productive. Replacing a diseased tree with a new one, while having the potential to increase the overall yield (output), incurs additional expenses, which reduces the net return. In other words, maximizing yield does not necessarily translate to maximizing profit as long there is a cost associated with the practice employed to bring about increased yields. In this case, the results suggest that it is best to fully exploit the partial resistance (tolerance) of the tree to the disease and allow the tree to continue to bear fruit even when infected, and control the vector (asian citrus psyllids) while prolonging the productivity of the tree by applying the foliar nutritional sprays. Replacing an infected but bearing tree with a new one will require a period of time before the replaced plant reaches maturity while incurring expenses. The stop light analysis also suggests that given that growers are much more inclined to prefer a situation with less variability and the smallest of downside risk, management strategy 2 appears to offer the best prospect.

\section{Conclusions}

The primary objective of this study was to assess the profitability of a hypothetical 5-acre tahiti lime orchard in southern Florida in the presence of citrus canker and citrus greening. To account for the uncertainty associated with the presence of the diseases, a stochastic budgeting technique was employed in the analysis, incorporating stochastic prices and yields based on discussions with industry experts and researchers. The results suggest that despite the presence of disease, it would be profitable to produce tahiti limes in southern Florida. This is because the tahiti lime offers some resistance to both citrus greening and canker and will produce even if minimal attention is paid to controlling the diseases. Management strategy 3 had the highest average net returns $(\$ 2466 /$ acre $)$, followed by strategy 2 (\$2292/acre) and strategy 1 (\$1182/acre).

Management strategy 2 had the highest probability of achieving the desired rates of return on investment. For a desired return on investment of $12 \%$, strategies 1,2 , and 3 , respectively, had a $33 \%, 100 \%$, and $96 \%$ chance of exceeding this value. For a desired return on investment of $15 \%$, strategies 1,2 , and 3 , respectively, had a $0 \%, 98 \%$, and $70 \%$ chance of exceeding this value.

The key finding emanating from the study or the lesson to be learned is that the production of tahiti limes in southern Florida can be profitable if steps are taken to manage the diseases, but contrary to the popular view, it might be better to wait until the trees become fully unproductive before disposing of them. That is, of the three options given, management strategy 2 offers the best prospect in terms of high net returns and highest probability of achieving or surpassing the desired rates of return on investment.

\section{Literature cited}

Barry, P.J., P.N. Ellinger, J.A. Hopkin, and C.B. Baker. 2000. Financial management in agriculture. 6th ed. Interstate Publ., Danville, IL.

Crane, J.H. and J.L. Osborne. 2011. Growing "tahiti" limes in the home landscape. EDIS No. CH093. 25 Nov. 2013. $<$ http://edis.ifas.ufl.edu/ch093>.

Dewdney, M. and J.H. Graham. 2012. Florida citrus pest management guide: Citrus canker. EDIS No. CG040. 25 Nov. 2013. <http://edis.ifas.ufl.edu/cg040>

Dewdney, M.M., P.D. Roberts, J.H. Graham, K.R. Chung, and M. Zekri. 2009. Homeowner fact sheet: Citrus canker. EDIS No.
PP116. 25 Nov. 2013. <http://edis.ifas. ufl.edu/ppl16>.

Food and Agriculture Organization of the United Nations. 2012. Detailed trade data. 25 Nov. 2013. <http://faostat. fao.org/site/535/default.aspx\#ancor>.

Florida Department of Agriculture and Consumer Services. 2013. Citrus canker program. 25 Nov. 2013. <http:// www.freshfromflorida.com/DivisionsOffices/Plant-Industry/Pests-Diseases/ Citrus-Canker-Program>.

Folimonova, S.Y., C.J. Robertson, S.M. Garnsey, S. Gowda, and W.O. Dawson. 2009. Examination of the responses of different genotypes of citrus to Huanglongbing (citrus greening) under different conditions. Phytopathology 99:1346-1354.

FreshFruitPortal.com. 2011. U.S. authorities turning back Mexican limes. 25 Nov. 2013. <http://www.freshfruitportal. com $/ 2010 / 12 / 14 /$ us-authoritiesturning-back-mexican-limes $/$ ?country= unitedstates>

Morris, A. and R.P Muraro. 2008. Economic evaluation of citrus greening management and control strategies. EDIUS No. FE712. 25 Nov. 2013. <http:// edis.ifas.ufl.edu/FE712>.

Morris, A., R.P. Muraro, and W.S. Castle. 2011. Optimal grove replanting to mitigate endemic HLB. Citrus Ind. 92(4):12-16.

Muraro, R.P. 2010. Planting and annual cultural maintenance costs for resetreplacement trees in a Florida citrus grove2010. 25 Nov. 2013. <http://www.crec. ifas.ufl.edu/extension/economics/pdf/ planting_and_annual_reset_2010.pdf $>$.

Richardson, J.W. 2006. Simulation for applied risk management. Dept. Agr. Econ., Agr. Food Policy, Texas A\&M Univ., College Station, TX.

Richardson, J.W., W.J. Lemmer, and J.L. Outlaw. 2007. Bio-ethanol production from wheat in the winter rainfall region of South Africa: A quantitative risk analysis. Intl. Food Agribusiness Mgt. Rev. 10(2):181-204.

Richardson, J.W. and J.L. Outlaw. 2008. Ranking risky alternatives: Innovations in subjective utility analysis. Wessex Inst. Technol. Trans. Info. Commun Technol. 39:213-224.

Roy, M., C.O. Andrew, and T.H. Spreen. 1996. Persian lime in North America: An economic analysis of the production and marketing channels. Florida Sci. Source Publ., Lake Alfred, FL.

Spann, T.M., R.A. Atwood, J.D. Yates, and J.H. Graham. 2008a. Dooryard citrus production: Citrus canker disease. EDIS 


\section{Production and Marketing Reports}

No. HSl130. 25 Nov. 2013. <http:// edis.ifas.ufl.edu/hs382>.

Spann, T.M., R.A. Atwood, J.D. Yates, M.E. Rogers, and R.H. Brlansky. 2008b. Dooryard citrus production: Citrus greening disease. EDIS No. HS383. 25 Nov. 2013. <http://edis.ifas.ufl.edu/HS383>.

Spann, T.M., R.A. Atwood, M.M. Dewdney, R.C. Ebel, R. Ehsani, G. England, S. Futch, T. Gaver, T. Hurner, C. Oswalt, M.E. Rogers, F.M. Roka, M.A. Ritenour, and M. Zekril. 2010. IFAS guidance for
Huanglongbing (greening) management EDIS No. HS 1 165. 25 Nov. 2013 <http://edis.ifas.ufl.edu/hs1165>.

Spreen, T.H. 2000. The citrus industries of the United States and Mexico after NAFTA. Revista Chapingo Serie Horticultura 6(2):145-152.

U.S. Department of Agriculture. 2012a. Fruit and vegetable truck rate report. 25 Nov. 2013. <http://search.ams.usda. gov/mnsearch/MNSearchResults.aspx $>$.
U.S. Department of Agriculture. 2012b. GATS home. Data access: Standard query. 25 Nov. 2013. <http://www.fas. usda.gov/gats/default.aspx>.

U.S. Department of Agriculture. 2013. Fruit and tree nut yearbook. Per capita consumption of citrus fruit. USDA Table G42. 25 Nov. 2013. <http://usda.mannlib. cornell.edu/MannUsda/viewDocumentInfo. do?documentID=1377>. 